\title{
Use of Ratiometric Probes with a Spectrofluorometer for Bacterial Viability Measurement
}

\author{
Jérôme Cléach ${ }^{1,2,3,4,5}$, Denis Watier ${ }^{1}$, Bruno Le Fur ${ }^{6}$, Thomas Brauge ${ }^{7}$, Guillaume Duflos ${ }^{7}$, Thierry Grard ${ }^{1+*}$, \\ and Philippe Lencel ${ }^{1+}$ \\ ${ }^{1}$ Université Littoral Côte d'Opale, EA 7394 - ICV - Institut Charles Viollette, USC ANSES - ULCO, F-62200 Boulogne-sur-Mer, France \\ ${ }^{2}$ Université de Lille, F-59000 Lille, France \\ ${ }^{3}$ Université d'Artois, F-62000 Arras, France \\ ${ }^{4}$ Institut national de la recherche agronomique (INRA), 75338 Paris, France \\ ${ }^{5}$ ISA Lille, F-59046 Lille, France \\ ${ }^{6}$ PFI Nouvelles Vagues (PFINV), F-62200 Boulogne-sur-Mer, France \\ ${ }^{7}$ ANSES, Laboratoire de Sécurité des Aliments, Boulevard du Bassin Napoléon, F-62200 Boulogne-sur-Mer, France
}

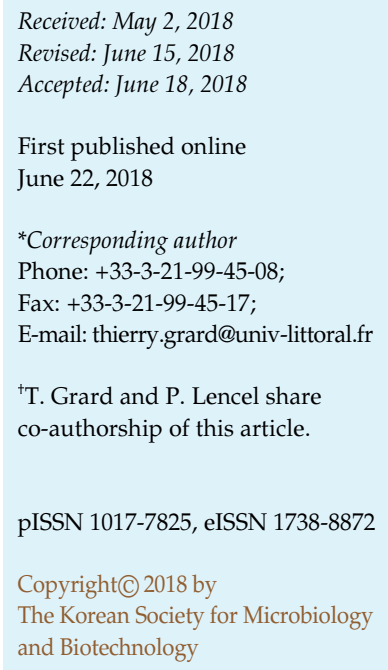

\begin{abstract}
Assessment of microorganism viability is useful in many industrial fields. A large number of methods associated with the use of fluorescent probes have been developed, including fluorimetry, fluorescence microscopy, and cytometry. In this study, a microvolume spectrofluorometer was used to measure the membrane potential variations of Escherichia coli. In order to estimate the sensitivity of the device, the membrane potential of E. coli was artificially disrupted using an ionophore agent: carbonyl cyanide 3-chlorophenylhydrazone. The membrane potential was evaluated using two ratiometric methods: a Rhodamine 123/ 4',6-diamidino-2-phenylindole combination and a JC-10 ratiometric probe. These methods were used to study the impact of freezing on E. coli, and were compared with the conventional enumeration method. The results showed that it was beneficial to use this compact, easy-touse, and inexpensive spectrofluorometer to assess the viability of bacterial cells via their membrane potential.
\end{abstract}

Keywords: Bacterial viability, Escherichia coli, fluorescence techniques, membrane potential

\section{Introduction}

To determine the effect of physical or chemical antimicrobial agents, there is a need to develop rapid methods that are able to evaluate cell viability. Bacterial strain viability depends on a number of characteristics: the membrane integrity, enzyme activity, membrane potential $(\Delta \Psi)$, and nucleic acid integrity. There are many fluorescent probes that make it possible to quantify and measure these cellular characteristics [1]. A large number of methods for viability assessment are related to the loss of membrane integrity and increases in membrane permeabilization [2]. These techniques use double labeling: probes able to cross bacterial membranes or probes able to cross only damaged membranes. The combination of the two staining techniques is used to evaluate the integrity and therefore the viability of bacterial cells. This study focused on another parameter: the membrane potential (MP; $\Delta \Psi$ ) involved in cell energy production. The MP is closely correlated with membrane integrity and the physiological state of bacteria [3]. Rhodamine 123 (Rh123), oxonol, and carbocyanine dyes are the main fluorescent compounds used to evaluate the MP. Their level of penetration into the cell is strongly correlated with the MP value. Many studies [1,4-6] have used the fluorescence technique to assess bacterial viability and its correlation with the MP. The emergence of new techniques, instruments, and specific probes has enabled researchers to evaluate bacterial strain viability. In a number of studies, flow cytometry has been used to determine the bacterial MP [7-9]. However, this method presents multiple drawbacks: 
a relative elevated cost of purchase and maintenance, and the need for specialized skills to operate the instrument.

The aim of this study was to carry out a comparison of two methods to determine the bacterial physiological state by MP evaluation in Escherichia coli (E. coli), used as a model for the microvolume spectrofluorometer. This fluorometer allows us to measure the fluorescence of molecules in solution, such as DNA and proteins, and small colloid particles such as bacteria [10, 11]. The reliability of this instrument using double labeling and ratiometric probes was evaluated. For this study, two cationic fluorescent dyes were used for MP evaluation: Rh123 and JC-10. These two probes have been used widely in the context of mitochondrial MP studies [12]. Rh123 has been described as a relatively effective probe on isolated mitochondria and is a good marker of the MP in bacteria [7, 8, 13]. Here, Rh123 staining was associated with 4',6diamidino-2-phenylindole (DAPI) staining in order to establish a ratio between a vitality stain and counter stain [14]. This ratiometric approach is also used in the LIVE/ DEAD BacLight bacterial viability kit [15-17]. The second probe used, JC-10, is a more recent compound and is a ratiometric probe. JC-10 reacts like 3,3'-diethyloxacarbocyanine iodide $\left(\mathrm{DiOC}_{2}\right)$ [4]. When the membrane potential is disrupted, the probe essentially takes a monomeric form and yields a green fluorescence. When the membrane potential is optimal, the probe aggregates and yields a red fluorescence. The ratio of the red to green fluorescence correlates with the level of the MP. Only JC-1, an older version of JC-10 with weaker water solubility, has previously been tested for MP evaluation in E. coli cells [18]. To validate the method developed in this study, carbonyl cyanide 3-chlorophenylhydrazone (CCCP) was used as a conventional MP depolarizer [19] at various concentrations. The effect of freezing at $-20^{\circ} \mathrm{C}$ and $-80^{\circ} \mathrm{C}$ was also tested to validate the reliability of this method and correlate the MP with viability.

\section{Materials and Methods}

\section{Strains and Medium}

The gram-negative strain of E. coli (UN 3373) used in this study was sourced from the collection of the Institut Pasteur in Paris, France. Cells were grown in LB (Luria-Bertani) medium at $37^{\circ} \mathrm{C}$. E. coli in cells the stationary phase were inoculated in fresh LB medium and grown for $4 \mathrm{~h}$ in order to obtain bacteria in the exponential phase.

\section{Chemical Substances}

Rh123, JC-10, DAPI, and CCCP were purchased from Sigma-
Aldrich. Phosphate-buffered saline (PBS) was purchased from PAN-Biotech and dimethyl sulfoxide (DMSO) from ThermoFisher Scientific. Rh123 $(2.6 \mu \mathrm{M}$ and $1 \mathrm{mg} / \mathrm{ml})$ and DAPI $(10 \mathrm{mg} / \mathrm{ml})$ stock solutions were prepared in ultra-pure water, and CCCP was dissolved in DMSO.

\section{DAPI Staining}

A NanoDrop 3300 microvolume spectrofluorometer (Ozyme, France) was used to estimate the bacterial concentration in suspension. A protocol for DAPI staining of E. coli was designed. The DAPI fluorescence intensity was correlated to the number of cells analyzed. Five concentrations of bacteria in the exponential phase (corresponding to different absorbance values at $600 \mathrm{~nm}$ : $0.15,0.3,0.4,0.7$, and 1) were stained in $1 \mathrm{ml}$ of PBS at a final concentration of $5 \mu \mathrm{g} / \mathrm{ml}$ at $37^{\circ} \mathrm{C}$ for $10 \mathrm{~min}$ in the dark. Cells were centrifuged at $9,000 \times g$ for $3 \mathrm{~min}$ and the supernatant containing free DAPI was removed. The pellet was suspended in PBS and DAPI fluorescence was analyzed with the microvolume spectrofluorometer.

\section{Membrane Potential Evaluation}

Rh123 and JC-10 were used to evaluate the bacterial MP following the method of Matsuyama [20], with modifications. E. coli cells in the stationary phase were inoculated in fresh LB medium and grown for $4 \mathrm{~h}$ in order to obtain bacteria in the exponential phase. During the exponential phase, the MP value is high [21-24]. Bacteria were harvested by centrifugation at $9,000 \times g$ for $3 \mathrm{~min}$ and then suspended in PBS $(1 \mathrm{ml})(\mathrm{pH}=7.4)$. The absorbance at $600 \mathrm{~nm}$ was adjusted to 0.3 , corresponding to approximately $10^{8}$ cells $/ \mathrm{ml}$. Then, $1 \mathrm{ml}$ of the preparation was treated with the depolarizer CCCP $(0.5,1$, or $20 \mu \mathrm{M})$ or DMSO $(1 \mu \mathrm{l})$ (negative control) and incubated for $30 \mathrm{~min}$ at $37^{\circ} \mathrm{C}$. DAPI (final concentration $=5 \mu \mathrm{g} / \mathrm{ml}$ ) was added to the suspension at $10 \mathrm{~min}$ before the end of the incubation only for Rh123 staining. After incubation, the cells were centrifuged at 9,000 $\times g$ for $3 \mathrm{~min}$ and the supernatant was eliminated. The pellet was resuspended in PBS with Rh123 at a final concentration of $10 \mu \mathrm{g} / 1$ or with JC-10 (according to the mitochondrial MP kit instructions: MAK160; Sigma, France) for $30 \mathrm{~min}$ at $37^{\circ} \mathrm{C}$ in the dark. After incubation and only for Rh123 staining, bacteria were centrifuged and the supernatant containing excess free Rh123 was eliminated. The pellet was resuspended in $1 \mathrm{ml}$ of PBS and centrifuged at 9,000 $\times g$ for $3 \mathrm{~min}$. The pellet was resuspended in $50 \mu \mathrm{l}$ of PBS and rhodamine fluorescence was analyzed with the microvolume spectrofluorometer and by microscopy.

To measure the impact of freezing on the MP, a centrifugation step was added $(9,000 \times g, 3 \mathrm{~min})$ in the cases of frozen bacterial samples (stored at $-20^{\circ} \mathrm{C}$ or $-80^{\circ} \mathrm{C}$ with or without $15 \%$ DMSO during $24 \mathrm{~h}$ ) and the corresponding unfrozen control. This centrifugation step was realized just after thawing the samples in order to remove any trace of DMSO before JC-10 labeling owing to DMSO toxicity toward cells and to avoid possible effects of DMSO on the JC-10 probe dispersion. 


\section{Epifluorescence Microscopy}

Microscopic analysis was performed with a Zeiss HBO-50 microscope (Microvision Instruments, France). In brief, $5 \mu \mathrm{l}$ of each sample was observed on glass slides under cover slips with an $\times 40$ oil immersion objective lens. For Rh123 staining observation, the microscope settings were $90 \mathrm{msec}$ of excitation, fineness 4 , and luminosity -15 . For DAPI staining observation, the microscope settings were $90 \mathrm{msec}$ of excitation, fineness 4 , and luminosity -10 .

\section{Microvolume Spectrofluorometer Settings}

The NanoDrop 3300 spectrofluorometer was initially designed for nucleic acid and protein quantitation. However, it is possible to create methods to configure new analyses for different fluorophores. Thus, a method for DAPI and Rh123 probes was created. The software proposes a fluorescence profiler in order to select the best excitation source for each fluorophore. The UV LED was chosen as the excitation source (excitation maximum $=365 \mathrm{~nm}$ ) for the DAPI probe, and the white LED (excitation range $=460$ $650 \mathrm{~nm}$ ) for Rh123, even though blue LED can also be effective. A $2 \mu \mathrm{l}$ sample was used for each measurement and a blank was generated with PBS. For each sample, five measurements were acquired.

\section{Viability Determination}

In order to correlate bacterial mortality with disruption of the MP, bacterial counts were performed using the spread plate technique with $1 \mathrm{ml}$ of sample in the plate count agar medium.
Five samples were tested: untreated, freezing at $-20^{\circ} \mathrm{C}$, freezing at $-20^{\circ} \mathrm{C}$ with $15 \%$ DMSO, freezing at $-80^{\circ} \mathrm{C}$, and freezing at $-80^{\circ} \mathrm{C}$ with $15 \%$ DMSO. Enumeration was carried out after $24 \mathrm{~h}$ of incubation in $37^{\circ} \mathrm{C}$. The freezing inactivation level was reported as log inactivation, according to Gao et al. [25]:

Log inactivation $=\left(\log _{10} N-\log _{10} N_{0}\right)$

where $N_{0}=$ cell concentration before freezing treatment $N=$ cell concentration after freezing treatment

\section{Statistical Analysis}

The statistical analysis and graphs were generated with SPSS 17 software. Each experiment was performed at least in triplicate. The data were expressed as the mean \pm standard deviation. Unpaired two-sample $t$-tests were used to express the significance of difference $(p<0.05)$ between means, and Levene's test to determine the homogeneity of variance.

\section{Results}

\section{E. coli Permeabilization Analysis by Epifluorescence Microscopy}

E. coli labeling and its control by epifluorescence microscopy made it possible to validate the cell staining protocol. The DAPI and Rh123 concentrations yielded uniform cell staining (visible microscopy not shown).
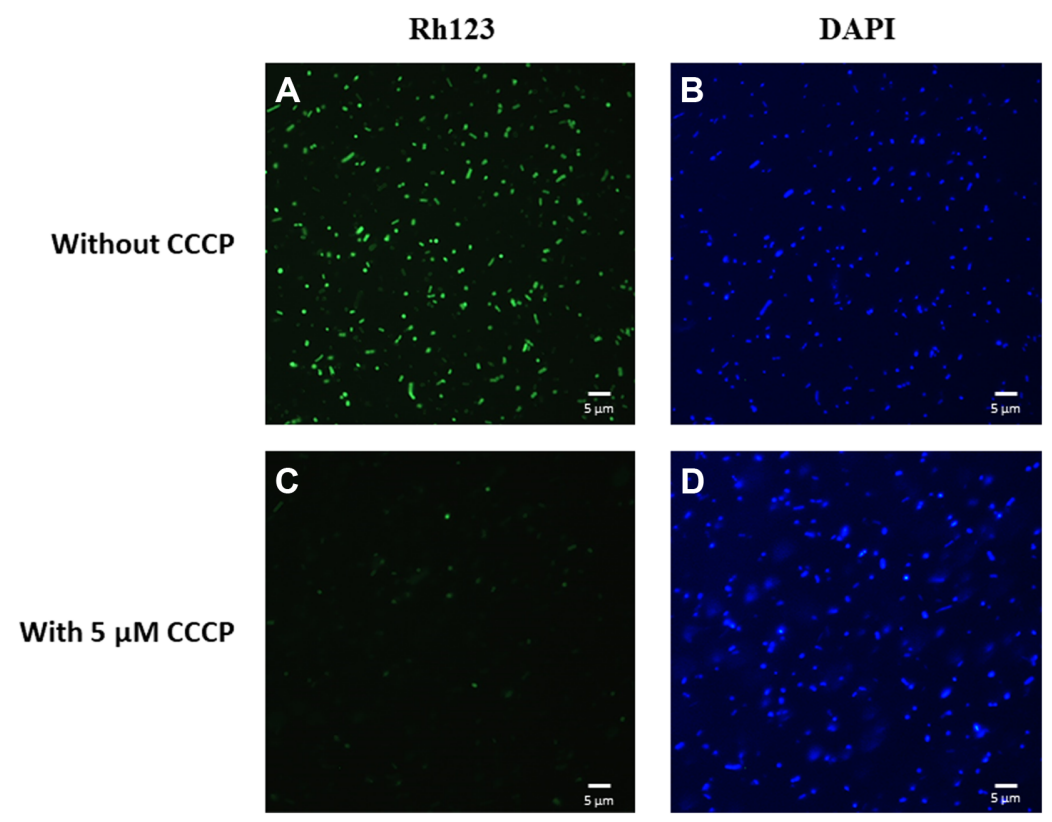

Fig. 1. Epifluorescence microscopy of Escherichia coli stained with Rhodamine 123 (Rh123) and DAPI without carbonyl cyanide 3chlorophenylhydrazone (CCCP) (A and B) or with $5 \mu \mathrm{M}$ CCCP treatment (C and $\mathbf{D})$.

A 5- $\mu 1$ sample was observed on glass slides under coverslips with an $\times 40$ oil immersion objective lens. For Rh123 staining observation, the microscope settings were $90 \mathrm{msec}$ of excitation, fineness 4 , and luminosity -15. For DAPI staining observation, the microscope settings were 90 msec of excitation, fineness 4 , and luminosity -10 . 

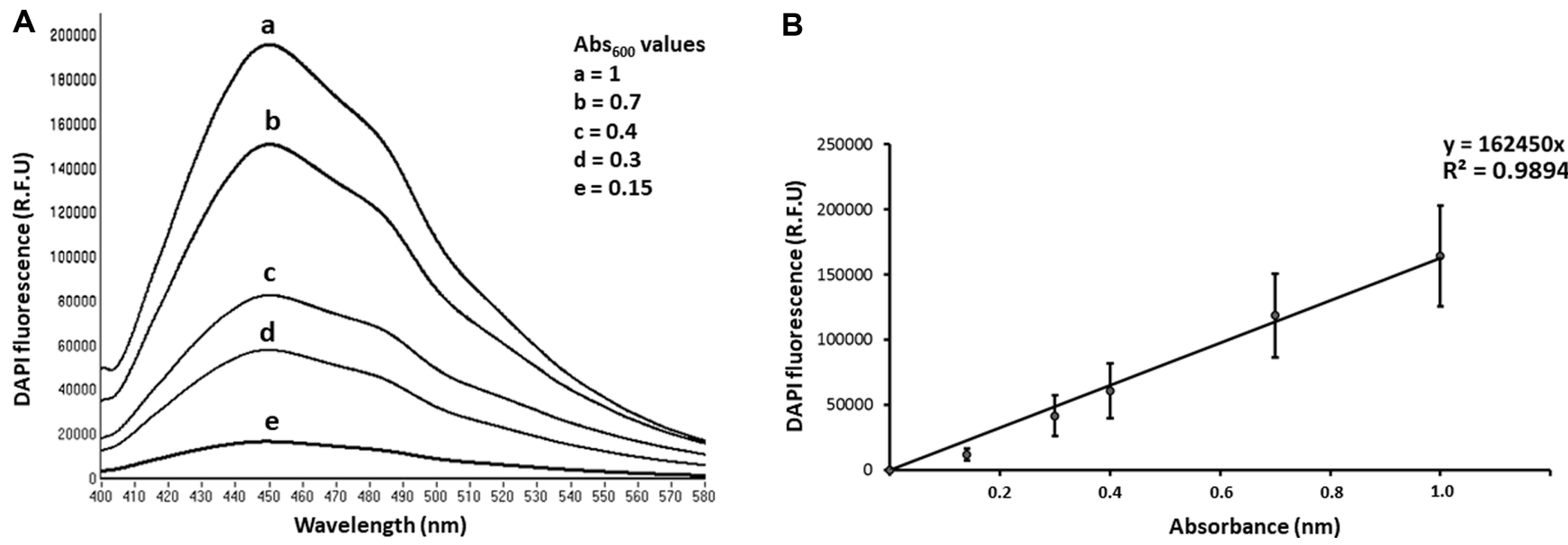

Fig. 2. Effects of Escherichia coli concentration on fluorescence measurements obtained with NanoDrop software.

(A) DAPI fluorescence spectra for different concentrations of E. coli. $\mathrm{Abs}_{600}$ values are respectively $\mathrm{a}=1 ; \mathrm{b}=0.7 ; \mathrm{c}=0.4 ; \mathrm{d}=0.3$; $\mathrm{e}=0.15$. (B) Regression line with error bars for DAPI fluorescence measurements versus concentration of E.coli. Data represent three independent experiments $(n=3)$.

Without CCCP treatment, the Rh123 (Fig. 1A) and DAPI staining degrees (Fig. 1B) were highly intense. Bacterial incubation in PBS enabled maintenance of significant MP. In the absence of nutrients in the medium, CCCP led to loss of the MP and a significant drop in Rh123 fluorescence (Fig. 1C). After treatment with CCCP $(5 \mu \mathrm{M})$, the MP was disrupted and the percentage of stained cells decreased strongly. However, bacterial membrane permeabilization by CCCP did not appear to affect DAPI staining (Fig. 1D).

\section{Bacterial Concentration Assessment after DAPI Staining}

The DAPI probe strongly interacts with DNA and allows staining of cells like bacteria. The ability of the NanoDrop 3300 to measure particle fluorescence in the range of $1 \mu \mathrm{m}$ (suitable for bacteria) was first studied to evaluate bacterial concentrations after DAPI staining. Different concentrations of bacteria, corresponding to different values of absorbance at $600 \mathrm{~nm}(0.15,0.3,0.4,0.7$, and 1$)$ were stained with DAPI, and the corresponding fluorescence profiles were obtained with NanoDrop software (Fig. 2A). The maximum wavelength emission was obtained at $450 \mathrm{~nm}$, corresponding to DNADAPI complex spectral data. The DAPI fluorescence intensity was directly proportional to the bacterial concentration $\left(\mathrm{R}^{2}=0.9894\right)$ (Fig. 2B).

The protocol included different centrifugation steps of bacteria, followed by pellet resuspension. For these reasons, a minimum absorbance of 0.1 was used even though the sensitivity of the method enabled us to work at much lower concentrations of bacteria. At very high concentrations $\left(\mathrm{Abs}_{600}>1\right)$, the fluorescence levels were very high but remained linear. Based on these observations, the best bacterial concentration range was chosen to be 0.1 to $1 \mathrm{Abs}_{600}$.

\section{Membrane Potential Evaluation}

The bacterial MP was evaluated by two fluorescent probes: Rh123 and JC-10, with the bacterial suspension at $\mathrm{Abs}_{600}=0.3$. The ionophore agent CCCP at different concentrations $(0.5,1$, and $20 \mu \mathrm{M})$ was used to validate the staining protocol. In order to set up the best conditions for MP evaluation, the staining was carried out at $37^{\circ} \mathrm{C}$ and $\mathrm{pH}$ 7.4 [23]. Fluorescence signals obtained after Rh123 and DAPI staining are shown in Fig. 3. The Rh123 fluorescence decreased in a dose-dependent manner with CCCP concentrations (Fig. 3A). In the presence of the bacteria with or without CCCP treatment, a red shift to $527 \mathrm{~nm}$ was observed (Fig. 3A.a). This Rh123 spectral property was described for the first time by Emaus et al. [12]. Free Rh123 in aqueous solution had an emission maximum at $524 \mathrm{~nm}$ (Fig. 3A.b). The dose effect was not found for DAPI staining (Fig. 3B). There was no interference between the two emission spectra of DAPI and Rh123. In order to correlate the MP-related fluorescence with a number of bacteria, the ratio between the Rh123 fluorescence and the DAPI fluorescence was used. The ratios (Rh123 fluorescence/ DAPI fluorescence) decreased in a dose-dependent manner with CCCP concentrations (Fig. 3C). In the presence of $\mathrm{CCCP}$, the Rh123/DAPI ratio values decreased significantly from $0.5 \mu \mathrm{M}$ to $20 \mu \mathrm{M}$ (Fig. 3C).

JC-10 is a lipophilic cationic probe. On the emission 
A

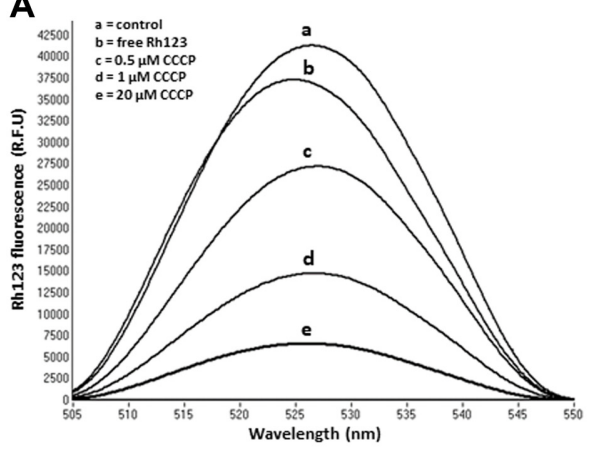

B

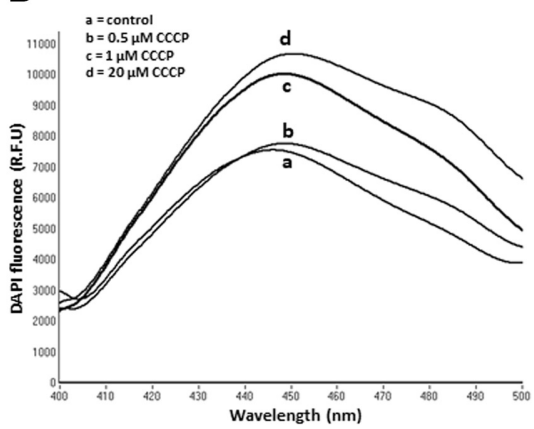

C

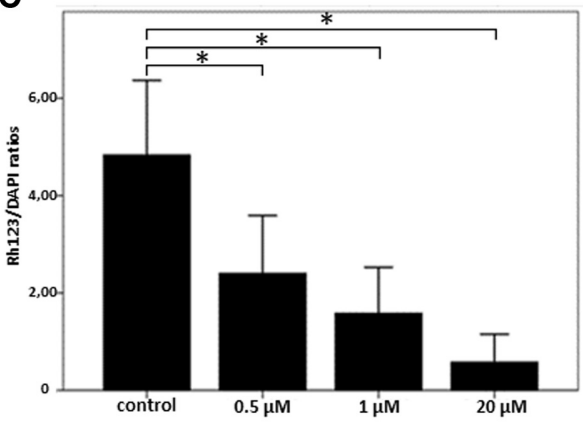

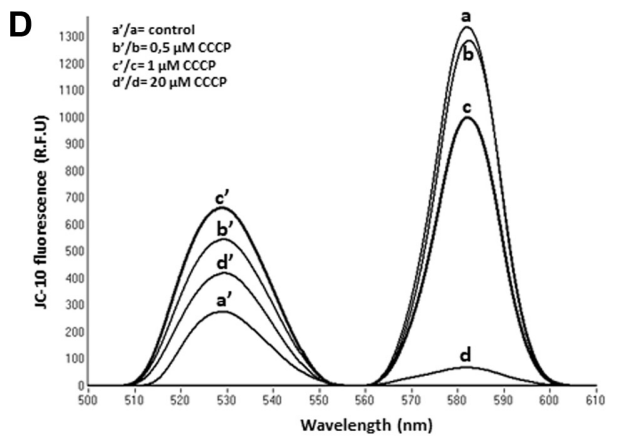

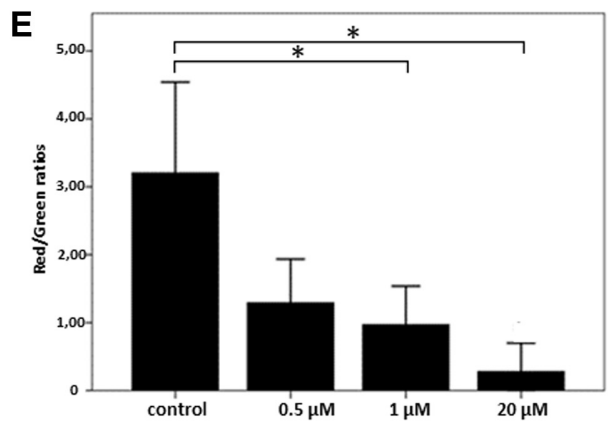

Fig. 3. CCCP effect on the Escherichia coli membrane potential.

(A) Fluorescence measured with Rh123 and different concentrations of carbonyl cyanide 3-chlorophenylhydrazone $(\mathrm{CCCP}): \mathrm{a}=\mathrm{control}$; $\mathrm{b}=\mathrm{free}$ Rh123; c $=0.5 \mu \mathrm{M}$ CCCP; $\mathrm{d}=1 \mu \mathrm{M} \mathrm{CCCP;} \mathrm{e}=20 \mu \mathrm{M}$ CCCP. (B) Fluorescence measured with DAPI and different concentrations of CCCP: a = control; $\mathrm{b}=0.5 \mu \mathrm{M} \mathrm{CCCP;}=1 \mu \mathrm{M} \mathrm{CCCP;} \mathrm{d}=20 \mu \mathrm{M} \mathrm{CCCP}$. (C) Rh123/DAPI ratios with different concentrations of CCCP (from 0.5 to $20 \mu \mathrm{M}$ ). (D) Fluorescence measured with JC-10 and different concentrations of CCCP: $\mathrm{a}^{\prime} / \mathrm{a}=$ control; $\mathrm{b}^{\prime} / \mathrm{b}=0.5 \mu \mathrm{M} \mathrm{CCCP} ; \mathrm{c}^{\prime} / \mathrm{c}=1 \mu \mathrm{M} \mathrm{CCCP} ; \mathrm{d}^{\prime} / \mathrm{d}=$ $20 \mu \mathrm{M}$ CCCP. (E) Red/green ratios (JC-10) with different concentrations of CCCP (from 0.5 to $20 \mu \mathrm{M}$ ). Significance for between-comparisons: ${ }^{*} p<0.05$. Fluorescence measurements and standard deviations represent three independent experiments $(n=3)$.

spectrum (Fig. 3D), we observed a peak at $582 \mathrm{~nm}$, which corresponded to the red fluorescence and therefore to the J aggregate form of JC-10 (polarized bacteria) (Fig. 3D.a,b,c,d), and a peak at $531 \mathrm{~nm}$, which corresponded to the green fluorescence and the monomer form of JC10 (depolarized bacteria) (Fig. 3D.a', $\left.b^{\prime}, c^{\prime}, d^{\prime}\right)$. On untreated bacteria (control: Fig. 3D.a and $a^{\prime}$ ), the high MP was characterized by significant red fluorescence. CCCP treatment disrupted the $\mathrm{MP}$, which was characterized by an increase in green fluorescence in a dose-dependent manner (Fig. 3D. $b^{\prime}, c^{\prime}, d^{\prime}$ ). For JC-10 staining, the 582 (red)/531 (green) ratio was observed to evaluate the bacterial MP. This ratio (red/ green) decreased in a dose-dependent manner with CCCP concentration (Fig. 3E). The measurement of the CCCP action by the ratiometric calculation Rh123/DAPI (Fig. 3C), and the use of the ratiometric probe JC-10 (Fig. 3D), gave identical results.

\section{E. coli Membrane Potential and Viability Assessments}

The effect of freezing (at $-20^{\circ} \mathrm{C}$ and $-80^{\circ} \mathrm{C}$ ) and the protective role of DMSO were examined on bacterial MP and bacterial survival (Fig. 4). Viability was followed using the serial dilutions agar plating method, and the MP was estimated by the use of both methods (Rh123/DAPI and JC-10). The number of E. coli in samples stored at $-20^{\circ} \mathrm{C}$ was significantly lower (about 4.5 log units) than the fresh sample (Figs. 4A and 4B). The effect of freezing on E. coli cell death was less marked at $-80^{\circ} \mathrm{C}$ (4 log units abatement). Under both these conditions $\left(-20^{\circ} \mathrm{C}\right.$ and $\left.-80^{\circ} \mathrm{C}\right)$, a cryoprotective effect was observed in the presence of DMSO (Figs. 4A and 4B). For the Rh123/DAPI ratios, after freezing of $24 \mathrm{~h}$ at $-20^{\circ} \mathrm{C}$ or $-80^{\circ} \mathrm{C}$, very weak Rh123 uptake was observed in bacteria compared with the control (Fig. 4C). However, when cells were frozen with DMSO, the Rh123/DAPI ratios were higher than those in cells without DMSO pretreatment (Fig. 4C). Measuring the Rh123/DAPI ratio makes it possible to differentiate the loss of viability in the different conditions of conservation. Concerning JC-10 staining, the results showed that the $\mathrm{red} /$ green ratios strongly decreased after freezing at $-20^{\circ} \mathrm{C}$ 
A

\begin{tabular}{|c|c|}
\cline { 2 - 2 } \multicolumn{1}{c|}{} & Number of cells $/ \mathbf{~ m I}$ \\
\hline Control & $1.14 \times 10^{8}$ \\
\hline$-20^{\circ} \mathrm{C}$ & $4.30 \times 10^{3}$ \\
\hline$-20^{\circ} \mathrm{C}$ DMSO & $5.42 \times 10^{6}$ \\
\hline$-80^{\circ} \mathrm{C}$ & $1.82 \times 10^{4}$ \\
\hline $\mathbf{- 8 0 ^ { \circ } \mathrm { C } \text { DMSO }}$ & $1.60 \times 10^{7}$ \\
\hline
\end{tabular}

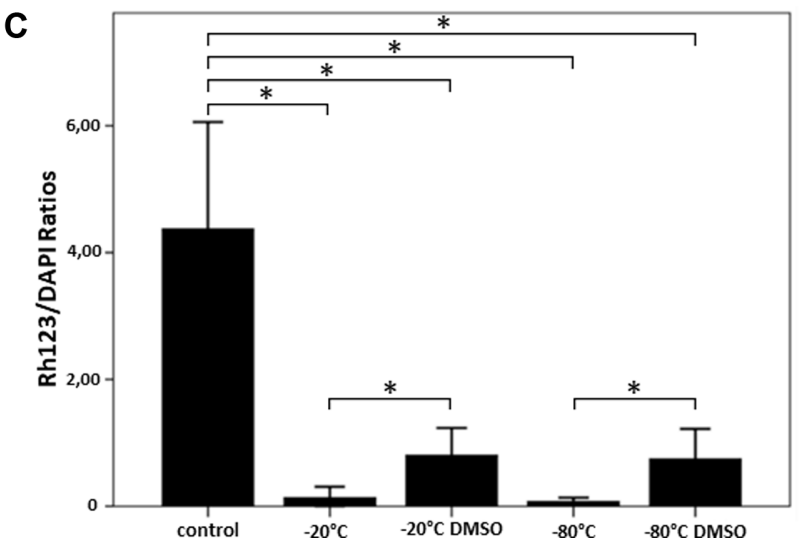

B

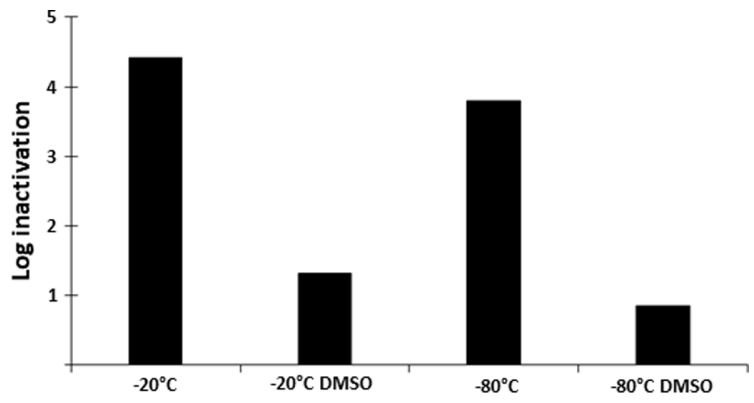

D

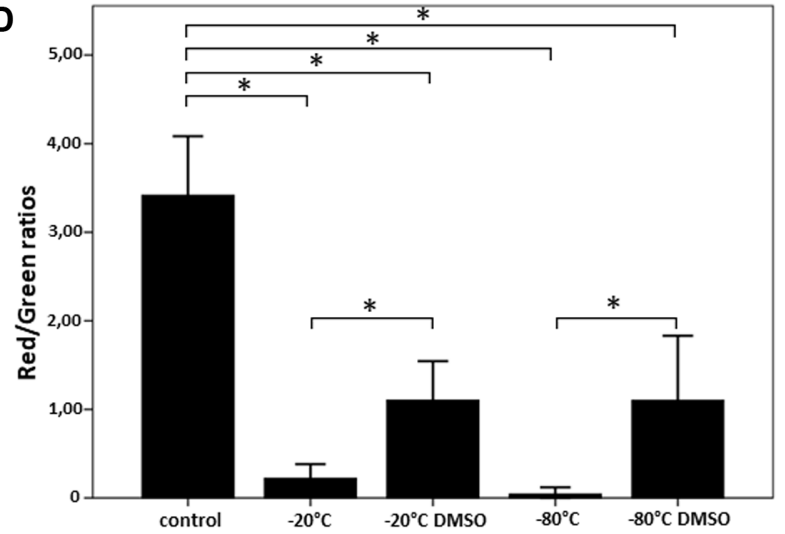

Fig. 4. Impact of freezing on the Escherichia coli viability and membrane potential.

(A) Viability assessment of $E$. coli after $24 \mathrm{~h}$ plate culture and various cell pretreatments $\left(-20^{\circ} \mathrm{C}\right.$ or $-80^{\circ} \mathrm{C}$ with or without dimethyl sulfoxide (DMSO)). (B) Log inactivation after freezing at $-20^{\circ} \mathrm{C}$ or $-80^{\circ} \mathrm{C}$ with or without DMSO. (C) Rh123/DAPI ratios with different freezing conditions $\left(-20^{\circ} \mathrm{C}\right.$ or $-80^{\circ} \mathrm{C}$ with or without DMSO) $(n=5)$. (D) Red/green ratios (JC-10) with different freezing conditions $\left(-20^{\circ} \mathrm{C}\right.$ or $-80^{\circ} \mathrm{C}$ with or without DMSO) $(n=5)$. Significance for between-comparisons: ${ }^{*} p<0.05$.

and $-80^{\circ} \mathrm{C}$ and the cryoprotective DMSO effect was once again significant (Fig. 4D). These results obtained with the JC-10 probe were in correlation with those obtained with the Rh123/DAPI ratios. Moreover, the results obtained with JC-10 and the Rh123/DAPI ratio using the fluorometer showed identical trends to those for the bacterial count. For both probes, MP values were correlated with the loss of bacterial viability. The viability and fluorescence losses were particularly high for freezing at $-20^{\circ} \mathrm{C}$ and $-80^{\circ} \mathrm{C}$. The log inactivation level was clearly higher when cells were not frozen with DMSO.

\section{Discussion}

In this research, two methods of measuring cell viability based on evaluation of the MP by fluorescence were studied. This study also showed the reliability of the NanoDrop 3300 in evaluating the number and MP of bacteria. The NanoDrop 3300 can be configured for three excitation sources: UV LED ( $\max =365 \pm 10 \mathrm{~nm})$, blue LED $(\max =470 \pm 10 \mathrm{~nm})$, and white LED (range $=460-650 \mathrm{~nm})$.
A wide range of fluorophores can be used to quantify bacteria and measure their viability. The thinness of the bandwidth of the UV LED and the blue LED ensures excitation specificity (useful for the double stains).

DAPI is widely used to stain DNA for quantification and fluorescent microscopy observation [26, 27]. Firstly, the limit of detection of the microvolume spectrofluorometer was determined by bacterial enumeration with DAPI. Different concentrations of $E$. coli corresponding to different values of absorbance at $600 \mathrm{~nm}$ (between 0.1 and 1) were stained and quantified with DAPI. The results showed a correlation between the amount of bacteria and the fluorescence intensity. The level of fluorescence increased proportionally with the increased concentration of bacteria. Our protocol required centrifugation and washing. For this reason, a minimum of $10^{7}$ bacteria/ml (approximately $\left.\mathrm{Abs}_{600}=0.05\right)$ was necessary to collect an apparent pellet. Conversely, high levels of bacteria $\left(\mathrm{Abs}_{600}>1\right)$ are not recommended owing to the sample pedestal contamination and a loss of linearity. DAPI is also widely used for total bacterial enumeration stains in environmental samples, 
according to Williams et al. [14]. Other probes such as Hoechst 33342 and Vibrant DyeCycle Violet can also be used $[21,28]$. They interact specifically with DNA and have an excitation wavelength in the UV range. The use of a UV excitable probe for counting will make it possible to use other probes to measure cell viability with double labeling.

In a second experiment, the ability of the NanoDrop 3300 to evaluate bacterial MP using double labeling was established. One of the originalities of the pair of probes (Rh123 and DAPI) is to combine them because they have very different excitation and emission properties: Rh123: ex/em: 507/524 nm (in water); DAPI: ex/em: 358/450 (when coupled with DNA). Any interaction between their excitation and emission wavelength is impossible. The wavelength emission of DAPI was $488 \mathrm{~nm}$ versus $450 \mathrm{~nm}$ for the DNA-DAPI complex. In the same way, a light red shift when bacteria were labeled with Rh123 (524 to $527 \mathrm{~nm}$ ) was observed. This phenomenon was described by Emaus et al. [12] in 1986 when isolated energized mitochondria were labelled with Rh123.

The notion of ratio has already been widely commented an in the literature and more particularly the propidium iodide (PI)/Syto 9 and PI/SYBR green ratios [29-31]. They have been used extensively in multiple studies and their efficiency has been confirmed by various techniques: flow cytometry, microscopy, and fluorimetry [7, 22, 32]. Therefore, we chose to use a ratiometric approach by coupling an MP probe (Rh123) with a counterstain (DAPI). Results showed that the Rh123/DAPI pair makes it possible to highlight the loss of MP under the action of CCCP in a dose-dependent manner [33, 34]. The loss of MP may be associated with membrane permeabilization and loss of viability. Bacteria in the exponential phase of growth were used to overcome the variations in MP associated with the growth stage [23]. Fluorescence microscopy showed relative homogeneity of the bacterial MP (homogeneity of fluorescence) under standard conditions (energizing), and the action of CCCP on bacteria also was homogeneous.

Similar results were obtained with the JC-10 ratiometric probe. The action of CCCP on bacteria resulted in a decrease in MP in a dose-dependent manner, with a decrease in red fluorescence (at $585 \mathrm{~nm}$ ), and an increase in green fluorescence $(530 \mathrm{~nm})$. The technical characteristics of the NanoDrop 3300 make it possible to clearly visualize the transition from red to green fluorescence. Like other ratiometric probes, such as $\mathrm{DiOC}_{2}[35,36]$, the JC-10 probe seems well adapted to the measurement of bacterial MP and to the loss of viability. This microvolume spectrofluorometer can therefore be used for the fluorescence measurement of colloids such as bacteria. The improved solubility of the JC10 probe has made it possible to increase performance compared with first-generation probes such as JC-1 [37].

Finally, these two methods were applied by measuring the effect of freezing at $-20^{\circ} \mathrm{C}$ and $-80^{\circ} \mathrm{C}$ on the viability of bacteria [25]. Freezing led to a fall in bacterial MP, which has been correlated with a loss of cell viability. These two ratiometric methods indicated the proportion of viable bacteria in a sample. The results obtained with the two methods have been correlated with the viability measurement by box count [35].

Our study showed a proportion of viable bacteria among a population of permeabilized bacteria. Various authors have observed viable bacteria among a positive PI-stained bacterial population [15, 16, 31, 38]. However, measuring bacterial permeabilization remains a simple approach to determine cell viability to measure the effectiveness of a treatment control $[39,40]$.

The Rh123/DAPI probe pair was particularly effective in measuring the loss of MP associated with physical or chemical treatments. The interest of this ratio was to compare the fluorescence (associated with a metabolic activity) to a bacterial concentration. This study showed that the JC-10 probe can be added to the list of fluorescent probes able to measure cell viability.

Continual progress in the development of probes and fluorescence techniques has provided improved approaches to the study of bacterial physiology. Owing to the technical characteristics of the microvolume spectrofluorometer (three excitation sources), it is possible to use a large number of probes for the measurement of cell viability. Many similar approaches could be considered for use on other biological colloids, such as mitochondria in suspension.

\section{Acknowledgments}

Jérôme Cléach is grateful to the Pôle Métropolitain de la Côte d'Opale council and PFI Nouvelles Vagues for their financial support of his PhD studies. The authors wish to thank Isabelle Cos from PFI Nouvelles Vagues and Irina Sadovskaya for her technical assistance.

This study was funded by the French government and the Hauts-de-France region in the framework of the CPER 2014-2020 MARCO project. This research was also funded by FranceAgrimer in the framework of the Altfish project.

\section{Conflict of Interest}

The authors have no financial conflicts of interest to declare. 


\section{References}

1. Joux F, Lebaron P. 2000. Use of fluorescent probes to assess physiological functions of bacteria at single-cell level. Microbes Infect. 2: 1523-1535.

2. Xu L, Zhang C, Xu P, Wang XC. 2017. Mechanisms of ultraviolet disinfection and chlorination of Escherichia coli: culturability, membrane permeability, metabolism, and genetic damage. J. Environ. Sci. (China) 65: 356-366.

3. Strahl H, Hamoen LW. 2010. Membrane potential is important for bacterial cell division. Proc. Natl. Acad. Sci. USA 107: 12281-12286.

4. McFeters GA, Feipeng PY, Pyle BH, Stewart PS. 1995. Physiological assessment of bacteria using fluorochromes. J. Microbiol. Methods 21: 1-13.

5. Breeuwer P, Abee T. 2000. Assessment of viability of microorganisms employing fluorescence techniques. Int. J. Food Microbiol. 55: 193-200.

6. Sträuber H, Müller S. 2010. Viability states of bacteria specific mechanisms of selected probes. Cytometry A 77: 623634.

7. Kaprelyants A, Kell D. 1992. Rapid assessment of bacterial viability and vitality by rhodamine 123 and flow cytometry. J. Appl. Microbiol. 72: 410-422.

8. Diaper J, Tither K, Edwards C. 1992. Rapid assessment of bacterial viability by flow cytometry. Appl. Microbiol. Biotechnol. 38: 268-272.

9. Novo DJ, Perlmutter NG, Hunt RH, Shapiro HM. 2000. Multiparameter flow cytometric analysis of antibiotic effects on membrane potential, membrane permeability, and bacterial counts of Staphylococcus aureus and Micrococcus luteus. Antimicrob. Agents Chemother. 44: 827-834.

10. Zhao J-Y, Jia L-M, Song W-Q, Zhang W-L, Fu Y-M, Zhang Y, et al. 2014. Labeling efficiency and toxicity evaluation of CdSe/ZnS quantum dots on Escherichia coli. J. Nanopart. Res. 16: 2424.

11. Chung J, Kang JS, Jurng JS, Jung JH, Kim BC. 2015. Fast and continuous microorganism detection using aptamer-conjugated fluorescent nanoparticles on an optofluidic platform. Biosens. Bioelectron. 67: 303-308.

12. Emaus RK, Grunwald R, Lemasters JJ. 1986. Rhodamine 123 as a probe of transmembrane potential in isolated rat-liver mitochondria: spectral and metabolic properties. Biochim. Biophys. Acta 850: 436-448.

13. Porter J, Pickup R, Edwards C. 1995. Membrane hyperpolarisation by valinomycin and its limitations for bacterial viability assessment using rhodamine 123 and flow cytometry. FEMS Microbiol. Lett. 132: 259-262.

14. Williams S, Hong Y, Danavall D, Howard-Jones M, Gibson D, Frischer M, et al. 1998. Distinguishing between living and nonliving bacteria: evaluation of the vital stain propidium iodide and its combined use with molecular probes in aquatic samples. J. Microbiol. Methods 32: 225-236.
15. Boulos L, Prevost M, Barbeau B, Coallier J, Desjardins R. 1999. LIVE/DEAD BacLight: application of a new rapid staining method for direct enumeration of viable and total bacteria in drinking water. J. Microbiol. Methods 37: 77-86.

16. Nescerecka A, Hammes F, Juhna T. 2016. A pipeline for developing and testing staining protocols for flow cytometry, demonstrated with SYBR Green I and propidium iodide viability staining. J. Microbiol. Methods 131: 172-180.

17. Bunthof CJ, van Schalkwijk S, Meijer W, Abee T, Hugenholtz J. 2001. Fluorescent method for monitoring cheese starter permeabilization and lysis. Appl. Environ. Microbiol. 67: 4264-4271.

18. Kumar A, Pandey AK, Singh SS, Shanker R, Dhawan A. 2011. Engineered $\mathrm{ZnO}$ and $\mathrm{TiO}_{2}$ nanoparticles induce oxidative stress and DNA damage leading to reduced viability of Escherichia coli. Free Radic. Biol. Med. 51: 1872-1881.

19. Kralj JM, Hochbaum DR, Douglass AD, Cohen AE. 2011. Electrical spiking in Escherichia coli probed with a fluorescent voltage-indicating protein. Science 333: 345-348.

20. Matsuyama T. 1984. Staining of living bacteria with rhodamine 123. FEMS Microbiol. Lett. 21: 153-157.

21. Monfort P, Baleux B. 1996. Cell cycle characteristics and changes in membrane potential during growth of Escherichia coli as determined by a cyanine fluorescent dye and flow cytometry. J. Microbiol. Methods 25: 79-86.

22. Comas J, Vives-Rego J. 1997. Assessment of the effects of gramicidin, formaldehyde, and surfactants on Escherichia coli by flow cytometry using nucleic acid and membrane potential dyes. Cytometry 29: 58-64.

23. Jiao N, Yang Y, Luo T. 2004. Membrane potential based characterization by flow cytometry of physiological states in an aerobic anoxygenic phototrophic bacterium. Aquat. Microb. Ecol. 37: 149-158.

24. Rezaeinejad S, Ivanov V. 2011. Heterogeneity of Escherichia coli population by respiratory activity and membrane potential of cells during growth and long-term starvation. Microbiol. Res. 166: 129-135.

25. Gao W, Leung K, Hawdon N. 2009. Freezing inactivation of Escherichia coli and Enterococcus faecalis in water: response of different strains. Water Environ. Res. 81: 824-830.

26. Sherr B, Sherr E, del Giorgio P. 2001. Enumeration of total and highly active bacteria. Methods Microbiol. 30: 129-159.

27. Muthukrishnan T, Govender A, Dobretsov S, Abed RM. 2017. Evaluating the reliability of counting bacteria using epifluorescence microscopy. J. Mar. Sci. Eng. 5: 4.

28. Silva F, Lourenço O, Queiroz JA, Domingues FC. 2011. Bacteriostatic versus bactericidal activity of ciprofloxacin in Escherichia coli assessed by flow cytometry using a novel farred dye. J. Antibiot. (Tokyo) 64: 321-325.

29. Xu C, Li J, Yang L, Shi F, Yang L, Ye M. 2017. Antibacterial activity and a membrane damage mechanism of Lachnum YM30 melanin against Vibrio parahaemolyticus and Staphylococcus aureus. Food Control 73: 1445-1451. 
30. Ma J, Kang M, Zhang Y, Guo X, Tian Z, Ding C, et al. 2017. Self-defense of Escherichia coli against damages caused by nanoalumina. Environ. Toxicol. Pharmacol. 55: 110-117.

31. Biggerstaff J, Le Puil M, Weidow B, Prater J, Glass K, Radosevich $\mathrm{M}$, et al. 2006. New methodology for viability testing in environmental samples. Mol. Cell. Probes 20: 141-146.

32. Breeuwer P, Abee T. 2004. Assessment of the membrane potential, intracellular $\mathrm{pH}$ and respiration of bacteria employing fluorescence techniques, pp. 1563-1580. In Kowalchuk GA, de Bruijn F, Head IM, Van der Zijpp AJ, van Elsas JD (eds.), Molecular Microbial Ecology Manual. Springer. Berlin.

33. Sekyere JO, Amoako DG. 2017. Carbonyl cyanide mchlorophenylhydrazine $(\mathrm{CCCP})$ reverses resistance to colistin, but not to carbapenems and tigecycline in multidrugresistant Enterobacteriaceae. Front. Microbiol. 8: 228.

34. Chimerel C, Field CM, Piñero-Fernandez S, Keyser UF, Summers DK. 2012. Indole prevents Escherichia coli cell division by modulating membrane potential. Biochim. Biophys. Acta 1818: 1590-1594.

35. Kennedy D, Cronin UP, Wilkinson MG. 2011. Responses of Escherichia coli, Listeria monocytogenes, and Staphylococcus aureus to simulated food processing treatments, determined using fluorescence-activated cell sorting and plate counting. Appl. Environ. Microbiol. 77: 4657-4668.

36. Guo N, Zang Y-P, Cui Q, Gai Q-Y, Jiao J, Wang W, et al. 2017. The preservative potential of Amomum tsaoko essential oil against E. coli, its antibacterial property and mode of action. Food Control 75: 236-245.

37. Novo D, Perlmutter NG, Hunt RH, Shapiro HM. 1999. Accurate flow cytometric membrane potential measurement in bacteria using diethyloxacarbocyanine and a ratiometric technique. Cytometry A 35: 55-63.

38. Berney M, Hammes F, Bosshard F, Weilenmann HU, Egli T. 2007. Assessment and interpretation of bacterial viability by using the LIVE/DEAD BacLight Kit in combination with flow cytometry. Appl. Environ. Microbiol. 73: 3283-3290.

39. Miyanaga K, Takano S, Morono Y, Hori K, Unno H, Tanji Y. 2007. Optimization of distinction between viable and dead cells by fluorescent staining method and its application to bacterial consortia. Biochem. Eng. J. 37: 56-61.

40. Lopez-Amoros R, Comas J, Vives-Rego J. 1995. Flow cytometric assessment of Escherichia coli and Salmonella typhimurium starvation-survival in seawater using rhodamine 123, propidium iodide, and oxonol. Appl. Environ. Microbiol. 61: 2521-2526. 